$400 / 2$

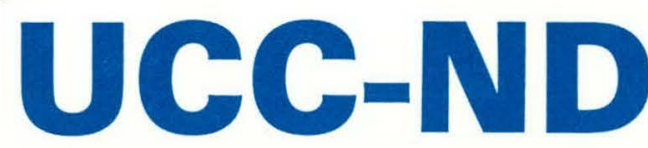

NUCLEAR DIVISION

UNION CARBIDE

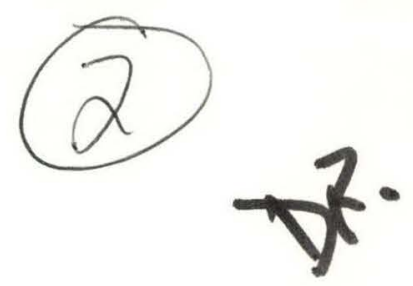

457

ORNL/CSD-100
Some Aspects of the Computer Simulation of Conduction Heat Transfer and Phase- Change Processes

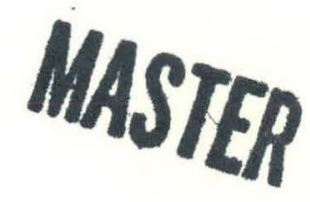

OPERATED BY

UNION CARBIDE CORPORATION FOR THE UNITED STATES DEPARTMENT OF ENERGY 


\section{DISCLAIMER}

This report was prepared as an account of work sponsored by an agency of the United States Government. Neither the United States Government nor any agency Thereof, nor any of their employees, makes any warranty, express or implied, or assumes any legal liability or responsibility for the accuracy, completeness, or usefulness of any information, apparatus, product, or process disclosed, or represents that its use would not infringe privately owned rights. Reference herein to any specific commercial product, process, or service by trade name, trademark, manufacturer, or otherwise does not necessarily constitute or imply its endorsement, recommendation, or favoring by the United States Government or any agency thereof. The views and opinions of authors expressed herein do not necessarily state or reflect those of the United States Government or any agency thereof. 


\section{DISCLAIMER}

Portions of this document may be illegible in electronic image products. Images are produced from the best available original document. 
Printed in the United States of America. Available from National Technical Information Service

U.S. Department of Commerce

5285 Port Royal Road, Springfield, Virginia 22161

NTIS price codes-Printed Copy: A03; Microfiche A01

This report was prepared as an account of work sponsored by an agency of the United States Government. Neither the United States Government nor any agency thereof, nor any of their employees, makes any warranty, express or implied, or assumes any legal liability or responsibility for the accuracy, completeness, or usefulness of any information, apparatus, product, or process disclosed, or represents that its use would not infringe privately owned rights. Reference herein to any specific commercial product, process, or service by trade name, trademark, manufacturer, or otherwise, does not necessarily constitute or imply its endorsement, recommendation, or favoring by the United States Government or any agency thereof. The views and opinions of authors expressed herein do not necessarily state or reflect those of the United States Government or any agency thereof. 


\section{SOME ASPECTS OF THE COMPUTER SIMULATION OF CONDUCTION HEAT TRANSFER AND PHASE-CHANGE PROCESSES}

A. D. Solomon

Date Published - April ig82
ORNL/CSD --100

DE82 013343

\section{COMPUTER SCIENCES}

at

Oak Ridge National Laboratory

Post Office Box $Y$

Oak Ridge, Tennessee 37830

Research Jolntly sponsored by the Applied Mathematical Sciences Research Program, Office of Energy Research; and the Division of Energy Storage Systems

Union Carbide Corporation, Nuclear Division operating the

- Oak Ridge Gaseous Diffusion Plant - Paducah Gaseous Diffusion Plant

- Oak Ridge Y-12 Plant

- Oak Ridge National Laboratory

under Contract No. W-7405-eng-26

for the

Department of Energy 
1. Introduction ................... 1

2. Moving Boundary Problems in Latent Heat Thermal

Energy Storage ................ 2

3. Weak Solution Methods ............... 5

4. Comparisons with Experiments ............. 6

5. Approximations and Exact Solutions .......... 7

6. Natural Convection in the Melt ............ 9

7. Sensitivity of Solutions ............. 10

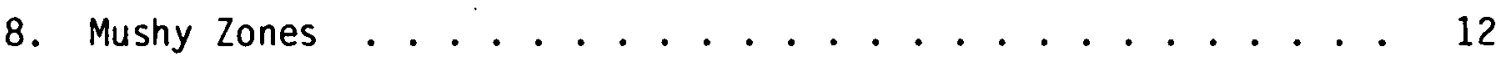

9. Pseudo-Intelligence in Heat Transfer Calculations . . . . . 12

References .................. 15 


\title{
SOME ASPECTS OF THE COMPUTER SIMULATION OF CONDUCTION HEAT TRANSFER AND PHASE CHANGE PROCESSES
}

\author{
Alan D. Solomon
}

\begin{abstract}
We discuss various aspects of phase change processes in materials including computer modeling, validation of results and sensitivity. .In addition, we examine the possible incorporation of cognitive activities in computational heat transfer.
\end{abstract}

\section{Introduction}

In this paper we discuss the solution of moving boundary problems arising in phase change processes. Such problems are distinguished by the fact that the domain in which a partial differential equation is to be solved constitutes one of the unknowns of the problem. The problem is typified by a situation in which we wish to simulate the temperature distribution in a melting or solidifying body. The problem is nonlinear, and due to the unknown and transient nature of the boundary, difficult to solve by most methods. To approach the problem it is good to initially.become acquainted with the applications and motivations that lead us to it. This is the subject of Section 1 where we briefly discuss some aspects of latent heat thermal energy storage.

The most natural way to solve moving boundary problems numerically for arbitrary boundary conditions, initial conditions or dimensionality is via the weak-solution or enthalpy method. Some of our recent work with this approach is discussed in Section 2. Of what use are our results? In Section 3 we compare them with experimental data involving $\mathrm{N}$-Octadecane Paraffin Wax. Indeed, we recount our experience of "discovering" the value of the thermal conductivity of the solid material from the analysis.

When we seek answers to qualitative questions, computational tools are only of limited assistance. Hence we must turn to the use of various approximation techniques. Some successes and limitations of these methods are discussed in Section 4 . In recent years the possibility of natural convection in the melt region has attracted increasing attention. However, under certain conditions the rapid heat transfer in the convecting melt region may trivialize the heat transfer process in this phase and greatly simplify the solution of the resulting problem. We will show how this can be for a simple, yet common problem, in Section 5 , involving experimentally observed results for $\mathrm{N}$-Octadecane Wax. To what extent is it possible to extrapolate computed results to the "real" 
world, knowing that the parameters used in your simulation are incorrect by some (possibly large) factor? To see this we must perform some kind of "sensitivity analysis" for our problem. We discuss the application of such an analysis to moving boundary problems via the weak solution formulation in Section 6 .

A point of some controversy among workers in the field concerns socalled "mushy" zones. We discuss some aspects of mushy zones in Section 7, including examples of each of three kinds of them. Finally, in Section 8 we turn to remarks about the possible use of artificial intelligence techniques in heat transfer calculations. Our discussion is qualitative, and yet, we hope, points the way to more concrete results.

Various aspects of the work described below have been obtained in collaboration with D. Wilson and J. Barhen of Union Carbide Corporation, R. Deal of Kalamazoo College, V. Alexiades, E. Keshock, and R. Irby of the University of Tennessee and $E$. Wacholder of the Haifa Technion. Needless to say, they have my deepest appreciation and gratitude.

\section{Moving Boundary Problems in Latent Heat Thermal Energy Storage}

One of the key problems in utilizing energy systems (active or passive solar, electrical, etc.) is how to store energy that is cheaply available at one place or time, for use at another place or time. The simplest example is found in areas where plentiful sunlight is available during the daytime, while the nights are cold. One would like to store the thermal energy obtained during the daytime for use at night. An approach to this problem, which was suggested already in the 1950's, was to store heat as the latent heat of melting in a "phase change material" (PCM) [35]. Thus the unwanted daytime heat could be used to melt the PCM; at night, we could withdraw this latent heat, refreeze the PCM, and use the heat to warm our house. To be of use in such an application, our PCM would have to have a high latent heat and, preferably, idealized values of thermal conductivity, specific heat and density.

In recent years interest in the use of PCM's for thermal energy storage has resulted in large-scale experimentation and work on modeling and design of innovative systems on a scale ranging from a single family residence to an electric power plant [37].

The heart of a latent heat thermal energy storage (LHTES) system is of course the PCM, encased in some kind of container, which is expected to melt and freeze "on demand." Good performance of such a system requires that we be able to store heat at a desired rate and withdraw it at a controllable rate. To know whether a particular LHTES system can do this is the central design problem for such a system; knowing this rests upon our understanding of the phase change process in the PCM itself and, hence, on our modeling of this process. Studying a model of this process leads us to the classical Stefan problem of finding the temperature and phase distribution of a material undergoing a change of phase [29]. 
In the Stefan problem we seek temperature and phase region distributions that will arise in a body which is initially in some known state and subjected to known conditions at its boundary with the passage of time. In the initial state it may be that the body was wholly liquid or solid, or a mixture of liquid and solid regions. The boundary conditions may be of Dirichlet type (temperature imposed), flux type (a known flux, such as direct solar gain), radiation (diffuse solar gain), or a combination of the above. Heat transfer in the body can generally be assumed to be via conduction (e.g., governed by the heat equation). However, experimental work in recent years has shown that natural convection in the melt region may indeed dominate heat transfer there, and hence, in many situations the conduction assumption fails [38]. In this case the above considerations must be modified. For LHTES applications, useful results can be obtained while limiting ourselves to one space dimension with appropriate symmetry assumed.

The nature of the application area dictates to some extent what kinds of information we wish to obtain from our analysis and computations. In the case of LHTES we take note of the following [29]:

a) the Stefan number [24] defined roughly as the ratio of the sensible heat to the latent heat in the PCM, should be small (e.g., less than 1);

b) we are interested in qualitative information about the process, such as the manner in which the rate of heat storage depends upon the number of pounds of PCM used;

c) we wish to have good engineering "rules of thumb" for designing a LHTES system; hence, we desire such "rules of thumb" for the behavior of our system at the PCM level;

d) the Biot number, defined roughly as the convective heat transfer to the PCM divided by the conductive heat transfer into the PCM, will not be too large.

Let us examine some typical situations arising in LHTES studies.

a) An experimental study of a PCM [25]: A plexiglass box is filled with a PCM; one face of the box consists of an aluminum plate through which water at predetermined varying temperatures is pumped. Thermocouples are placed at various distances from the plate. By adjusting the water temperature we can induce melting and solidification of the PCM. A typical scenario that might be of interest is where the PCM is initially in its solid phase at its melting temperature, and the box is oriented so that the aluminum face is on top. Beginning at time $t=0$, hot water at a temperature above the PCM melt temperature is pumped through the face. The PCM will thus melt from above; an identifiable phase change front is observed to move down into the box, leaving liquid PCM above it. and solid PCM below it. 
In this case there is an explicit formula for the temperature distribution and the phase boundary history [4]. This formula can be used to give us a check upon some of the "knowns" of our process, such asvalues of physical parameters. Similarly, it can also be used to form a basis for dealing with situations that are more realistic and general than that of (a). For example:

b) The box of (a) is now placed in a wall, and the water, instead of being pumped at high speed, is now simply flowing very slowly (perhaps by convection) through the plate.

In this case there is no longer a known explicit expression for the temperature distribution and phase change front history. To study our system we must use numerical or analytical procedures, attempting (if possible) to extrapolate from (a), at least for conditions in which the water flow speed is sufficiently high. The boundary condition at the aluminum face will now be convective, relying on our knowledge of the film coefficient from water to the surface.

c) A Trombe wall is a massive wall placed behind a large southfacing glass window of a house. Its purpose is to store solar energy during the day for release into the house at night. The Trombe wall is usually made of some material with a high specific heat, and because of its large mass, cannot be easily retrofitted into a house. It is natural to ask whether one can build a PCM Trombe wall, and for that matter, whether it would be of value to incorporate a PCM slab into an interior wall, floor or ceiling $[5,30]$.

In these cases our Stefan problem has now acquired time dependent boundary conditions in which multiple boundaries may appear and disappear. There is no longer a way to analytically model the phase change process since multiple fronts constitute a difficulty that we cannot overcome. We are thus driven to doing something else. It is most natural to use numerical methods to model such a system--and in particular, we need numerical methods which are themselves "weak" or independent of the front. A second alternative discussed in [30] is to attempt to replace this problem by an "equivalent" pure conduction process--a step that can be done exactly in very simple cases.

d) Air conditioners like to work all the time or not at all. They are least efficient when they are forced to turn on and off too often, and in this case their lifespans are shortened as well. Several years ago it was proposed (see [23]) that a PCM storage device be placed in the air conditioning loop of a house. The air conditioner would be low powered--too low for normal use in the house. However this air conditioner would work all of the time; when the "cold" that it produced was not needed by the house, it would be stored in the PCM. When the house did need cooling, this cooling (as well as dehumidification) was to be supplied by both the air conditioner and the PCM. The PCM 
container system was to consist of more than 1000 small tubes, containing PCM, and arranged in a grid through which air was to flow.

Our phase change problem now becomes very complex, since we are attempting to model a system of PCM containers under conditions that vary in time. Moreover, each container is acted upon by air that was exposed to the container before it, and so there is interaction between them. Clearly this problem has no explicit solution, and even computer simulation becomes a challenge, since simulations are to last for periods of months. We must thus seek other methods for studying this idea.

Of course we could go on and on describing increasingly complex LHTES systems. Moreover, this is but one area of application of moving boundary problems. Many others exist (see e.g., $[14,15,20,40]$ ) and we discuss some interesting problems in some of them in subsequent sections.

\section{Weak Solution Methods}

If the greatest difficulty in solving moving boundary problems lies in tracking the unknown phase boundary, and if in turn this phase boundary is determined by conditions of conservation of energy, then it is natu$r a l$ to seek a formulation of the phase change process which is based on the energy of the material and from which the phase boundary location is a natural consequence of solving energy conservation laws for the system. Thus any of the Stefan-type problems formulated in the last section can be formulated in terms of the specific internal energy of the system in such a way that we can avoid tracking the moving boundary. This is the basic idea of the weak solution or enthalpy methods which are currently the standard ones for solving phase change problems of any dimensionality and boundary conditions $[29,2,17]$.

Among the processes that we have dealt with using these methods are:

a) density changes inducing movement of the PCM in one dimension [29];

b) the presence of internal heat sources in the material;

c) multiply layered materials, such as a PCM layer between layers of other materials (extending.[28]);

d) coupled phenomena, such as those arising in binary alloy solidification with the phase front concentrations and temperatures related by an equilibrium phase diagram [41];

e) interaction between a PCM container and a flowing transfer fluid; 
f) two dimensional moist ground heat transfer with freezing;

g) multiple PCM containers in a duct $[22,23]$.

Studies of accuracy, applicability, and convergence of weak solution methods include the recent work of R. White (e.g., [39]).

\section{Comparisons with Experiments}

The purpose of the computer or analytical model is to interact with other activities including parallel experiments on materials of interest. One such study was made concerning the behavior of the PCM $\mathrm{N}$-Octadecane Paraffin Wax. The configuration used was the plexiglass box described in (a) of Section 2. This box was placed in a loop by means of which water at a predetermined temperature was pumped across its aluminum face, inducing phase changes in the wax. A number of thermocouples were placed in the material, and their temperatures recorded. The event where a phase boundary crosses a thermocouple can be recognized by a jump in the rate of change of the temperature recorded by that thermocouple in time. Let us consider one series of experiments in which the wax was frozen from an initially liquid state. The box was oriented with the aluminum face on the bottom to discourage natural convection in the liquid region.

In order to perform the computer simulation, the values of the following parameters are needed:

\begin{tabular}{|c|c|c|}
\hline k & $=$ thermal conductivity & $(\mathrm{kj} / \mathrm{m}-\mathrm{s}-\operatorname{deg} . \mathrm{C})$ \\
\hline$C$ & $=$ specific heat & $(\mathrm{kj} / \mathrm{kg}$-deg.c) \\
\hline 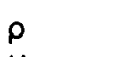 & $=$ densitty & $\left(\mathrm{kj} / \mathrm{m}^{3}\right)$ \\
\hline & $=$ latent heat & $(\mathrm{kj} / \mathrm{kg})$ \\
\hline melt & $=$ melt temperatur & $(\operatorname{deg} \cdot C)$ \\
\hline
\end{tabular}

We must admit of the possibility that $k, c$, and $\rho$ depend on the phase, and in particular, that they may differ strongly in the liquid and solid phases.

Over a range of experiments, sharp differences were noted between observations of when the phase front reached the thermocouple locations and when the simulations predicted that this would happen. By simply eliminating possible causes of the discrepancy, it was concluded that at least for the sample of the wax used, the thermal conductivity of the solid phase must be about 3.5 times as large as the value that appears in the literature [7]. Subsequent direct evaluations of the thermal conductivity in this PCM have verified the implications of the simulations [6]. This in turn has initiated other experiments on the thermal conductivity of mixtures of waxes which are now being carried out. 


\section{Approximations and Exact Solutions}

There are a number of ways to obtain approximations to the temperature and phase front history under simplifying assumptions on initial and boundary behavior. These include the quasi-stationarity assumption that $c$ an be made when the latent heat is very large and the sensible heat is very small. Under these conditions, the phase front is for all intents and purposes unmoving, and hence the temperature is essentially always in its steady state for the present location of the phase front. In a second set of approaches, due to Goodman and to Megerlin, we approximate the temperature distribution by a function of a suitable simple form in space and determine the values of time-dependent parameters entering this form via conservation or other related conditions [33]. An alternative approach is to combine these approximations with numerical simulation and curve fitting in order to escape from the constraints imposed by the analytical approximations. In this way a number of effective approximations have been obtained for simple phase change processes including the melting time of a simple body subject to a variety of boundary conditions [32, 26, 27], the surface temperature subject to convective boundary conditions [31], and estimates of the total thermal energy stored under various conditions $[29,19]$.

One example of the potential utility of analytical approximations is given by the example (d) of Section 2. Let us briefly consider this result.

Suppose that a cylinder of radius $R$ is filled with a PCM and placed in a stream of a transfer fluid. We assume that the PCM is initially in its solid state at the melting temperature $T_{\text {melt }}$ while the transfer fluid temperature is a constant $T_{L}>T_{\text {melt }}$. Then it can be shown [27] that the total time of melt of the PCM is given by the expression

$$
t_{\text {melt }} \approx\left(R^{2} / 2 \alpha S t\right)[1 / 2+1 / B i+.21 \mathrm{St}]
$$

where St is the Stefan number of the prucess, $B 1$ is the Biot number, and $\alpha$ is the thermal diffusivity of the liquid PCM,

$$
S t=c\left(T_{L}-T_{\text {melt }}\right) / H ; B i=h R / k .
$$

This relation is based upon the asumption that heat transfer to and within the cylinder is radially symmetric.

Let us now place $N$ such cylinders in the crossflow of a narrow transfer fluid channel. Then the transfer fluid entering the channel is cooled by losing heat to the first cylinder, further cooled by the second, and so on. Simultaneously, melting progresses in the first cylinder faster than in the second, which is faster than in the third, and so on. Can we model this process via expressions such as (5.1)? 
It turns out we can do just that. Using (5.1) and making some reasonable assumptions about the nature of the melting process, one can derive simple relations for the time needed to melt the jth cylinder, $j=1, N$, the temperature of the transfer fluid as a function of time, and the total energy stored in the entire system of cylinders at any time [22]. Using these relations we can save computing time for sizing or designing such a LHTES system. As an example, there has been an interest in the performance of such a system using a PCM derived from Glauber's salt placed in sausagelike "chubs." For one particular scenario, a weak solution computer simulation modeling each chub and the transfer fluid was compared with the approximate relations. It was found that to within the degree of accuracy required, the approximations constituted an accurate replacement for the computer program. In Table 1 we see the outlet air temperatures from an array of 24 chubs as a function of time.

Table 1. Computed and Approximate Air Outlet Temperatures

Time (hr) Computed (deg.C) Approximate (deg.C)

\begin{tabular}{rrr}
1 & 12.76 & 12.76 \\
3 & 12.76 & 12.76 \\
5 & 12.74 & 12.75 \\
7 & 12.71 & 12.72 \\
9 & 12.64 & 12.68 \\
11 & 12.52 & 12.56 \\
13 & 12.28 & 12.42 \\
15 & 11.86 & 12.17 \\
17 & 11.07 & 11.44 \\
19 & 9.67 & 10.47 \\
21 & 7.33 & 7.84 \\
23 & 4.59 & 4.44 \\
\hline
\end{tabular}

Generally speaking, approximation methods are well behaved when the Stefan and Biot numbers are small. It is of interest to point out that one of the most significant gaps in the theory of Stefan type problems lies in the lack of error estimates for the very commonly used approximations of Megerlin, Goodman, and others. One might ask whether one is really limited to small values of $\mathrm{St}$ and $\mathrm{Bi}$; it is interesting to note that approximations may fail to be qualitatively correct when they are not small. Let us look at an example of such a failing that appeared in the course of a design exercise by a private engineering firm involved in LHTES work.

We consider the melting of a semi-infinite PCM slab occupying the region $x>0$ due to convective heat transfer from a transfer fluid at $x=0$. The PCM is assumed to be initially in its solid phase at its critical temperature $T_{\text {melt }}$, while the transfer fluid is at the temperature $T_{L}>T_{\text {melt }}$. If the heat transfer coefficient was infinite, then the 
phase front would be determined by a Dirichlet type boundary condition in which the temperature $T_{L}$ would be assigned directly at $x=0$ :

$$
T(0, t)=T_{L}
$$

However, since $h$ is finite the boundary condition is of course

$$
-k T_{x}(0, t)=h\left(T_{L}-T(0, t)\right) .
$$

For all finite $h$ the phase boundary under condition (5.3) moves more slowly than it does under (5.2); this is a qualitatively correct property of the melting process and can be proved via the use of the corner point maximum principle [19]. Suppose that we apply the methods of Megerlin, Goodman, or the quasistationary approximation to (5.3). We would expect that the approximate boundary should still move more slowly than does the boundary for (5.2). However, analyzing this point shows that this assertion is not true [21] if $B i$ is not sufficiently small. This in turn means that one must be very cautious when applying approximation methods of this type, even if the numbers one obtains appear to be reasonable.

\section{Natural Convection in the Melt}

It has been observed (e.g., [38]) that natural convection in the melted region of a PCM is probabily the dominant mode of heat transfer in many cases. In a series of experiments following the setup described in (a) of Section 2, it was seen that in most cases natural convection plays a leading if not dominant role in the heat transfer process for melting and freezing of N-Octadecane Paraffin Wax. While at first glance one might be convinced that we must solve the system of Navier-Stokes equations in addition to some set of equations for the internal energy, there are many situations in which the natural convection simplifies the approximate solution of our problem appreciably. Let us consider one. such case drawn from our experiments.

Suppose that we are melting the wax in the box oriented in such a way that melting occurs from below, with the heated plate on the bottom. Let the $x$-axis measure the vertical distance from the face, and $x(t)$ be the location of the phase change front at time $t$. Suppose that the face temperature is $T_{L}>T_{m e l t}$ and that the $P C M$ is initially solid at its melting temperature.

We will make the hypothesis that (for small Stefan number) all of the heat transferred into the box from the transfer fluid goes into melting the PCM. Moreover, we assume that the melting front progresses very slowly compared to the convective transfer in the fluid. Hence, referring to any standard heat transfer source (e.g., [12]), we obtain a relation between the position of the melt front and the heat transfer 
coefficient due to convection. For the particular situation at hand, this relation essentially takes the form

$$
X(t)=A t^{B}
$$

where $A$ and $B$ depend upon the nature of the flow (laminar or turbulent convection). Comparison with experimental data shows an excellent fit between the $A$ and $B$ values for turbulent natural convection and from our experimental observations. Thus, at least for the case at hand, one can very easily overcome the implied difficulty of having convective heat transfer in the melt, and more generally, it would appear that LHTES problems can be dealt with merely by examining the extreme cases of fully turbulent convection or pure conduction in the melt.

\section{Sensitivity of Solutions}

A basic problem in using computers to solve problems lies in the question of whether the results obtained are accurate, correct, and physically meaningful. Accuracy would popularly mean that the numbers generated are close to the "exact solution" to an underlying problem--be it an experimental setup or a partial differential equation. Correctness means more: it means that qualitatively speaking, the algorithin is doing the correct things. It may fail if there is a programming bug or if the numerical algorithm is in some sense in error. "Physically meaningful" is connected to the fact that there is a "real world" interest in our solution; can our solution be used to satisfy that interest?

Sensitivity analysis is devoted to learning about the manner of dependence of certain elements of a model upon others. Examples of questions of interest in the heat transfer context would be: (a) What is the possible change in the total energy of a storage system induced by an uncertainty in the value of the density of the PCM of 10 percent? (b) What is the manner in which the thermal conductivity depends upon the temperature at a point? (c) Is it safe to set the specific heat equal to zero and use the quasistationary approximation in a phase change problem? If we begin to think along the lines of sensitivity theory, we are led to some very interesting questions about moving boundary problems. Let us raise some such questions.

It is "well known" that when the heat transfer coefficient for convective heat transfer from a heat transfer fluid tends to infinity, the process can be modeled by one in which the convective heat transfer boundary condition is replaced by one where the transfer fluid temperature is directly imposed upon the boundary. In essence we are asking how the solution to a phase change process (e.g., temperature, phase boundary) depends upon the heat transfer coefficient. Moving from very general existence results and using standard moment-type relations as well as a "corner-point" maximun principle for the heat equation, we have proved that indeed the solution does tend to that with imposed fluid temperature as the heat transfer coefficient tends to infinity [19]. 
It is "well known" that as the specific heat $c$ tends to zero, the solution to a Stefan problem will tend to the quasistationary solution where the temperature is always in its steady state for fixed phase change front. This too can be proved using a variety of moment relations and tools of real analysis [18].

It is "intuitively" clear that the solution to a Stefan-type problem should depend upon the parameters of the problem in a differentiable manner. This has recently been proved in [9] where the parameter in question is the surface heat flux.

A much deeper "sensitivity" problem arises when in place of a well defined mathematical problem, our formulation is a computer program and we are asked to "differentiate" one element of the program with respect to another. One direction that one can take is to formally differentiate the program itself, although in the absence of meaningful theoretical underpinnings, and in the presence of a substantial nonlinear factor in the moving boundary, one might hesitate to do this. Another possible approach is via the so-called "adjoint sensitivity analysis" which has been used with success for a number of large codes in engineering physics and other areas.

In sensitivity analysis we are basically interested in finding the derivative of some factor, say $G$, with respect to some other factor $f$. What $f$ and $G$ are depends upon the form of our problem and the nature of the questions that we are interested in. In particular, both $f$ and $G$ may well be large vectors consisting of many factors of interest. For our problem, for example, $f$ may well be a vector consisting of $k, c, p$, and the initial temperature function. The derivative in question is, say, a Gateaux derivative. We wish to compute this derivative, or sensitivity, with the least effort possible, since we will assume that our basic problem entails a substantial computational effort already. If we simply differentiate every element of our problem formulation with respect to each of the components of $f$, we will generate a possibly enormous computing problem which cannot be resolved. The adjolnt sensitivity analysis approach permits us to minimize this effort by requiring simply one "backward" computation for a backwards equation that is derived from our problem.

For the Stefan problem, an adjoint sensitivity analysis can be performed by using the internal energy formulation of the problem. For example, the problem in one dimension can be replaced by one for the degenerate parabolic equation

$$
e_{t}=\left(\alpha(e) e_{x}\right)_{x}
$$

where $\alpha(e)$ vanishes over the phase change region which is identified with the condition $0<\mathrm{e}<\mathrm{H}$. We can deal with (7.1) in a reasonably straightforward manner. Of course, for Dirichlet boundary conditions on a semi-infinite strip, the Stefan problem admits of an explicit solution from which the derivatives can be found explicitly. Some preliminary work on this solution has been done in [13]. 


\section{Mushy Zones}

If one observes a freezing or melting front on the microscopic level, he will see that the front is not sharp but is in reality composed of a thin layer of intermixed solid and liquid material. Indeed, we may identify the solidification process itself as one of local supercooling, dendritic growth, and subsequent freezing of the interspersed liquid $[10]$. The thin region between solid and liquid is sometimes referred to as a mushy zone.

If one places a sample of radioactive material in an insulated container, it may heat up and eventually melt with no external heat added. During the time after it reached its melt temperature and before it was liquid, it constituted a mushy zone.

If one applies the weak solution method to a melting or solidification problem, one will generally find that certain mesh points (perhaps many) lie in the interface zone and are neither liquid nor solid. This is especially true if one models the process by replacing the specific heat in the heat equation for the temperature by a delta-function whose strength is equal to the latent heat. This is no mushy zone!

The first kind of mushy zone was observed and measured in experiments done by Thomas and Westwater [36]; it was found that under steady state conditions its thickness varied inversely with the temperature gradient across a slab in which the experiment was carried out. Using that result, it is possible to define a model of solidification which admits of an explicit solution extending that of [4] for the problem without a mushy zone [34].

Problems of the second kind $c$ an be dealt with by using analytical techniques and/or numerical methods based on the weak solution approach. Results of this nature have been obtained in [2]. Existence results which are in principle applicable to such problems are found in [39].

Questions concerning phenomena of the third kind have arisen in connection with problems of binary alloy solidification. Nevertheless, as has been shown in [16], basic existence results for such problems would indicate that (assuming uniqueness) a mushy zone will not occur in such processes unless it is explicitly put into the problem formulation as in $[34,1]$.

\section{Pseudo-Intelligence in Heat Transfer Calculations}

In recent years we have spent some effort on simulations of an air preheating process aimed at increasing the performance of a heat pump in winter. It is known that the efficiency of a heat pump falls sharply as the inlet air temperature declines below about -4 degrees Centigrade. It is also known that at a depth of about 2 to 3 meters the ground temperature in the United States is above 10 degrees Centigrade. We are 
using both experimental and numerical methods to see if this can serve to preheat cold outside air which is then to be pumped into the heat pump cycle at the higher temperature.

It is simple to construct the simulation that we are using; its components are:

a) a duct, on the ground surface, through which air is being pumped at a known flow rate;

b) the ground below the duct, to a depth of < 3 meters;

c) a heat pump whose in let air is the outlet from the duct.

The simulation is to be for a winter period (up to 6 months). Since it is thought that freezing of the (moist) ground may occur, we use a twodimensional, enthalpy-based, heat conduction model for the ground. Because of a variety of problems associated with moisture and vapor migration in the ground we treat the ground heat transfer process as one of pure heat conduction. Heat exchange between ground surface and duct is assumed to be via convection with a known film coefficient. A comparison of the simulation with data collected from a house in Alcoa, Tennessee, in early 1980 showed excellent agreement (to within $1^{\circ} \mathrm{C}$ ) over a period of weeks for the predicted duct outlet air temperature. One might conclude that our simulation exercise is successful. Nevertheless, let us consider what we have and have not done up to this point. To ease our discussion, let $T_{i n}$, $T_{\text {out }}$ be the duct inlet and outlet air temperatures, FA the duct floor area, and $S$, the savings in electricity due to preheating the air.

What we have done:

a) we have performed a simulation for which no disagreement is seen to exist with observed data;

b) we have found no contradiction to the assumptions on which our model was built.

What we have not done:

Here our list is very long. Let us begin with the run that we made.

A) The program was not able to detect the recurrence of periodic or near-periodic patterns. It was not able to say things like "I have been in this situation before, and this is what happened then; let us see if it will happen again." If it could have done this, it would have avoided an extensive amount of calculation by simply leaping ahead in time until it encountered less familiar situations. 
B) The program should have been able to "learn" in what way Tout responded to changes in $T_{\text {in }}, F A$ and other factors (e.g., ground moisture)--noting that $T_{\text {in }}$ is time-dependent.

C) Of course, at the very least, it could have been programmed to establish simple relationships based on a statistical analysis of its computations [8].

D) While the program was running, large amounts of data were being generated. Very little of this data was seen by me, since I could not predict, a priori, what might be of interest. It is only after seeing the first run that I would recognize that some other factor would be of interest. Perhaps I would need to make an additional run after changing one output statement. Wouldn't it be good if the program could analyze its own data as it is generated, identifying." interesting" things, and telling us about them?

On a larger plane, it is of interest to write a "heat transfer learning" program, using a combination of known facts and intuitive rules of thumb at various levels of applicability, to lead us to new concepts and suggested experiments. Initial steps have been taken in a number of areas $[11,3]$ and have been suggested for heat transfer as well.

Our efforts up to this time have been aimed at developing a very simple learning code to interactively develop a heat transfer data base in LISP, and a subroutine package linked to the ground heat transfer code for analyzing its performance as it runs. Work is continuing in these directions. 


\section{REFERENCES}

[1] Alexiades, V. and Cannon, J., Free boundary problems in solidification of alloys, SIAM Jrni. of Mathematical Analysis 11 (1980) 254-264.

[2] Atthey, D., A finite difference scheme for melting problems, $\underline{J}$. Inst. Maths. Applics. 13 (1974) 353-366.

[3] Barr, A. and Feigenbaum, E., The Handbook of Artificial Intelligence, Vol. 1 (William Kaufmann, 1981).

[4] Carslaw, H. and Jaeger, J., Conduction of Heat in Solids, 2nd Edition (Oxford University Press, London, 1959).

[5] Chemical mixture is base of MIT's new solar system, Solar Heating and Cooling, April (1978) 24-27.

[6] Deal, R., Irby, R., Keshock, E., and Solomon, A., On the solidification of $\mathrm{N}-0$ ctadecane paraff in wax, Union Carbide Corporation Report No. ORNL/CSD-92, to appear.

[7] Hale, D., Hoover, M., and $0^{\prime} \mathrm{Neill}$, M., Phase change materials handbook, Report HREC-5183-2, Lockheed Missiles and Space Company, Huntsville, Alabama (September 1971).

[8] Herget, C., Method developed to model and to control complex systems, in: Electronics Engineering Quarterly Report UCRL50025-80-2 (Lawrence Livermore Laboratory, September 1980).

[9] Jochum, P., Differentiable dependence upon the data in a one-phase Stefan problem, Math. Meth. Appl. Sci. 2 (1980) 73-90.

[10] Kallungal, J. and Barduhn, A., Growth rate of an ice crystal in subcooled pure water, A.I.Ch.E. Jrnl. 23 (1977) 294-303.

[11] Lenat, D., On the ubiquity of discovery, AFIPS Proceedings (1978).

[12] McAdams, W., Heat Transmission, 3rd edition (McGraw Hill Book Company, New York, 1954).

[13] Mingle, J., Stefan problem sensitivity and uncertainty, Numerical Heat Transfer 2 (1979) 387-393.

[14] Ockendon, J. and Hodgkins, W., Moving boundary problems in heat flow and diffusion, in: Proceedings of a Conference at the University of Oxford, 1974 (Clarendon Press, London, 1975).

[15] Rubinstein, L:, The Stefan problem, A.M.S. Translations of Mathematical Monographs, Vo 1. 27 (American Mathematical Society, Providence, 1971). 
[16] Rubinstein, L., Solidification of a binary alloy, pp. 399-416 in: Vol. 1 of Free Boundary Problems, Proceedings of a seminar held in Pavia, September-October, 1979 (Instituto Nazionale di alta Matematica Francesco Severi, Rome, 1980).

[17] Shamsundar, N. and Sparrow, E., Analysis of multidimensional conduction phase change via the enthalpy model, Jrni. Of Heat Transfer (1975) 333-340.

[18] Solomon, A., Wilson, D., and Alexiades, V., The quasi-stationary approximation for the Stefan problem with a convective boundary condition, Union Carbide Corporation Report No. ORNL/CSD-84 (September 1981).

[19] Solomon, A., Alexiades, V., and Wilson, D., The Stefan problem with a convective boundary condition, Quarterly of Applied Mathematics, to appear.

[20] Solomon, A., On mathematical modeling of cryosurgical processes, Cryobiology, to appear.

[21] Solomon, A., On the limitations of analytical approximations for phase change problems with large Biot numbers, Letters in Heat and Mass Transfer 8 (1981) 475-482.

[22] Solomon, A., Some approximations of use in predicting the behavior of a PCM cylinder array, Letters in Heat and Mass Transfer 8 (1981) 237-246.

[23] Solomon, A., Simulation of a PCM storage subsystem for airconditioning assist, Union Carbide Corporation Report No. ORNL/CSD-77 (1981).

[24] Solomon, A., A note on the Stefan number in slab melting and solidification, Letters in Heat and Mass Transfer 8 (1981) 229235.

[25] Solomon, A. and Deal, R., The simulation of four pure conduction paraffin-wax freezing experiments, Union Carbide Corporation Report No. ORNL/CSD-74 (1981).

[26] Solomon, A., An expression for the melting time of a rectangular body, Letters in Heat and Mass Transfer 7 (1980) 379-384.

[27] Solomon, A., On the melting time of a simple body with a convection boundary condition, Letters in Heat and Mass Transfer 7 (1980) $183-188$.

[28] Solomon, A. and Serbin, C., TES-A program for simulating phase change processes, Union Carbide Corporation Report No. ORNL/CSD-51 (1979). 
[29] Solomon, A., Mathematical modeling of phase change processes for latent heat thermal energy storage, Union Carbide Corporation Report No. ORNL/CSD-39 (1979).

[30] Solomon, A., Design criteria in PCM wall thermal storage, Energy 4 (1979) 701-709.

[31] Solomon, A., A relation between surface temperature and time for a phase change process with a convective boundary condition, Letters in Heat and Mass Transfer 6 (1979) 192-200.

[32] Solomon, A., Melt time and heat flux for a simple PCM body, Solar Energy 22 (1979) 251-257.

[33] Solomon, A., The applicability and extendability of Megerlin's method for solving parabolic free boundary problems, pp. 187-202 in: $[40]$.

[34] Solomon, A., Alexiades, V., and Wilson, D., A mushy zone model with an exact solution, Union Carbide Corporation Report No. ORNL/CSD-91, to appear.

[35] Telkes, M., Solar cooking ovens, Solar Energy 3 (1959) 1-11.

[36] Thomas, L., and Westwater, J., Microscopic study of solid-liquid interfaces during melting and freezing, Heat Transfer-Houston, Chemical Engineering Progress Symposium Series 41 (1963) 155-164.

[37] U.S. Department of Energy, Proceedings of the DOE Thermal and Chemical Storage Annual Contractor's Review Meeting, McLean, Virginia, October, 1980 (U.S. DOE Conf. 801055, March 1981).

[38] Viskanta, R., Bathelt, A:, and Hale, Jr., N., Latent heat-offusion energy storage: experiments on heat transfer during solid-liquid phase change, in: Proceedings of the 3rd Miami International Conference on Alternative Energy Sources, December 15-17, 1980, Bal Harbour, Florida.

[39] White, R., An enthalpy formulation of the Stefan problem, preprint, to be published.

[40] Wilson, D., Solomon, A., Boggs, P., Moving boundary problems, in: Proceedings of a symposium at Gat inburg, Tennessee, September, 1977 (Academic Press, New York, 1978).

[41] Wilson, D., Alexiades, V., and Solomon, A., Progress with simple binary alloy solidification problems, to appear in: Proceedings of the conference on moving boundary problems held in Montecatini, Italy, July 1981 (Springer-Verlag). 


\section{THIS PAGE \\ WAS INTENTIONALLY \\ LEFT BLANK}


ORNL/CSD-100

Distribution Category UC-32\& $94 a$

\section{INTERNAL DISTRIBUTION}

1. Central Research Library

2. K-25. Plant Library

3. ORNL Patent Office

4. $Y=12$ Technical Library, Document Reference Section

5. Laboratory Records - RC

6- 7. Laboratory Records Department

8. J. Barhen

9. K. 0. Bowman

10. H. P. Carter/CSD X-10 Library

11. R. E. Funderlic

12. L. J. Gray

13. E. Greenbaum
14. G. Grossman

15. H. W. Hoffman

16. B. J. Kedl

17. R. MCGill

18. C. A. Serbin

19. K. E. Shultzl Biometrics Library

20-24. A. D. Solomon

25. J. J. Tomlinson

26. V. R. R. Uppuluri

27. R. C. Ward

28. D. G. Wilson

29. C. Weisbin

\section{EXTERNAL DISTRIBUTION}

30. Or. Yoshiyuki Abe, Energy Systems Division, Electrotechnical Laboratory, 1-1-4 Umezono, Sakura-mura, Ni ihari-gun, Ibaraki, JAPAN

31. Dr. S. D. Augustynowicz, Frigitronics of Connecticut, 770 River Road, Shelton, Connecticut 06484

32. Dr. Donald M. Austin, ER-15, Division of Engineering, Mathematical \& Geosciences, Office of Basic Energy Sciences, Germantown Building, Room J-311, DOE, Washington, DC 20545

33. Dr. Miriam Bareket, Department of Mathemat1cs, Tel Aviv University, Tel Aviv, ISRAEL

34. Professor Shlomo Breuer, Department of Mathematics, Tel Aviv University, Ramat Aviv, Tel Aviv, ISRAEL

35. Dr. T. D. Butler, T-3, Hydrodynamics, Los Alamos National Laboratory, P.0. Box 1663, Los Alamos, New Mexico 87545

36. Dr. Bill L. Buzbee, C-3, Applications Support \& Research, Los Alamos National Laboratory, P.0. Box 1663, Los Alamos, New Mexico 87545

37. Dr. Baruch Cahlon, Department of Mathematics, Oakland University, Rochester, Michigan 48063

38. Professor John Cannon, Department of Mathematics, Washington State University, Pullman, Washington 99164 
39. Dr. Jagdish Chandra, Director, Mathematics Division, U.S. Army Research Office, P.O. Box 12211, Research Triangle Park, North Carolina 27709

40. Dr. T. C. Chawla, Building 208, Argonne National Laboratory, 9700 South Cass Avenue, Argonne, Illinois 60439

41. Dr. L. Lynn Cleland, Engineering Research Division, Lawrence Livermore National Laboratory, P.0. Box 808, Livermore, California 94550

42. Dr. James S. Coleman, Division of Engineering, Mathematical and Geo-Sciences, Office of Basic Energy Sciences, Department of Energy, ER-17, MC G-256, Germantown, Washington, DC 20545

43. Dr. Sam Coriell, U.S. National Bureau of Standards, Mathematical Analysis Section, Washington, D.C. 20234

44. Dr. James Corones, Ames Laboratory, Iowa State University, Ames, Iowa 50011

45. Professor John Crank, School of Mathematical Studies, Brunel University, Kingstone Lane, Uxbridge, UB8 3PH, Middlesex, ENGLAND

46. Dr. Ralph Deal, Department of Chemistry, Kalamazoo College, Kalamazoo, Michigan 49001

47. Professor Charles DePrima, Department of Mathematics, California Institute of Technology, Pasadena, California 91125

48. Dr. Marvin n. Erickson, Computer Technology, Systems Department, Pacific Northwest Laboratory, $\bar{P} .0$. Box yygy, Rfchl drud, Washington 99352

49. Professor Antonio Fasano, Instituto Matematico U. Dini, V. Le Morgagni 67/A, 50134 Firenze, ITALY

50. Professor Avner Friedman, Department of Mathematics, Northwestern University, Evanston, Illinois 60201

51. Dr. Bill Fthenakis, Building 475, Brookhaven National Laboratory, Upton, New York 11973

52. Professor Nima Geffen, Department of Mathematics, Tel Aviv University, Tel Aviv, ISRAEL

53. Professor Roland Glowinski, IRIA-LABORIA, Domaine de Voluceau, Rocquencourt, B.P. 105, 78150 Le Chesnay, FRANCE

54. Professor Max Goldstein, Courant Institute of Mathematical Sciences, New York University, 251 Mercer Street, New York, New York 10012 
55. Dr. Jeff Gordon, Institut for Desert Research, Sede-Boker Campus, ISRAEL

56. Dr. Philomena G. Grodzka, Lockheed Missiles \& Space Co., Inc., 4800 Bradford Drive, Huntsville, Al abama 34505

57. Dr. Joel Harband, Rehov Hibner, 13/6, Petach Tikuah, ISRAEL

58. Dr. Robert E. Huddleston, Applied Mathematics Division, 8332, Sandia Laboratories, Livermore, California 94550

59. Professor Alfred Inselberg, Department of Mathematics, Ben Gurion University, Beersheva, ISRAEL

60. Professor Eugene Isaacson, New York University, Courant Institute of Mathematical Sciences, 251 Mercer Street, New York, New York 10012

61. Dr. Malvin Kalos, New York University, Courant Institute of Mathematical Sciences, 251 Mercer Street, New York, New York 10012

62. Professor Shoshana Kamin, Department of Mathematics, Tel Aviv University, Ramat Aviv, Tel Aviv, ISRAEL

63. Dr. N. D. Kaushika, Centre of Energy Studies, Indian Institute of Technology, Hauz Khas, New Delhi 110029, INDIA

64. Dr. Robert J. Kee, Applied Mathematics Division, 8331, Sandia Laboratories, Livermore, California 94550

65. Professor Herbert Keller, Department of Mathematics, California Institute of Technology, Pasadena, California 91125

66. Professor Peter D. Lax, Director, Courant Institute of Mathematical Sciences, New York University, 251 Mercer Street, New York, New York 10012

67. Professor Carlos Lozano, University of Delaware, Department of Mathematics, Newark, Delaware 19711

68. Ms. Judith A. Mahaffey, Statistics, Systems Department, Pacific Northwest Laboratory, P.0. Box 999, Richland, Washington 99352

69. Dr. Paul C. Messina, Applied Mathematics Division, Argonne National Laboratory, Argunne, Illinois 60439

70. Dr. George Michael, Computation Department, Lawrence Livermore National Laboratory, P.0. Box 808, Livermore, California 94550

71. Dr. Allan I. Michaels, Argonne National Laboratory, Building 362, Argonne, Ill inois 60439 
72. Professor Willard Miranker, IBM Research Center, P.0. Box 218, Yorktown Heights, New York 10598

73. Dr. Arun S. Mujumdar, Department of Chemical Engineering, McGill University, 3480 University Street, Montreal, Quebec H3A 2A7 CANADA

74. Dr. Basil Nichols, T-7 Mathematical Modeling and Analysis, Los Al amos National Laboratory, P.0. Box 1663, Los Alamos, New Mexico 87545

75. Professor Aharon Nir, c/o Dr. Chin Fu Tsang, Earth Sciences Division, Lawrence Berkeley Laboratory, Berkeley, California 94720

76. Dr. Ben Noble, Math Research Center, University of WisconsinMadison, 610 Walnut Street, Madison, Wisconsin 53706

77. Professor J. Ockendon, Oxford University, Computing Laboratory, oxford, ENGLAND

78. Professor Ben 0liver, Department of Metallurgical Engineering, University of Tennessee, Knoxville, Tennessee 37919

79. Or. T. Ozawa, Electrotechnical Laboratory, 1-1-4 Umezono, Sakuramura, Niihari-gun, Ibaraki, JAPAN

80. Professor Beresford Parlett; Department of Mathematics, University of California at Berkeley, Berkeley, California 94720

81. Dr. Ronald Peier1s, Applied Mathematics Department, Brookhaven National Laboratory, Upton, New York 11973

82. Dr. Carl Quong, Computer Science and Applied Mathematics Department, Lawrence Berkeley Laboratory, Berkeley, California 94720

83. Professor Amos Richmond, Head, Desert Research Institute, Sde Boker, ISRAEL

84. Professor Aharon Roy, Department of Chemical Engineering, University of the Negev, Beersheva, ISRAEL

85. J. N. Rogers, Div. 8324, Sandia Laboratories, Livermore, California 94550

86. Dr. Milton E. Rose, Director, ICASE, Mail Stop 132C, NASA Langley Research Center, Hampton, Virginia 23665

87. Dr. S. Saxena, Department of Chemical Engineering, Indian Institute of Technology, New Delhi-110 029, INDIA

88. Dr. Lawrence F. Shampine, Numerical Mathematics Division, 5642, Sandia Laboratories, P.0. Box 5800, Albuquerque, New Mexico 87115 
89. Professor Bernard Sherman, Department of Mathematics, New Mexico Tech, Socorro, New Mexico 87801

90. Mr. R. Siegel, Head, Analytical Fluid Mechanics Section, NASA, Lewis Research Center, Cleveiand, Ohio 44135

91. Dr. E. M. Sparrow, Department of Mechanical Engineering, University of Minnesota, 125 Mechanical Engineering, 111 Church Street, SE, Minneapolis, Minnesota 55455

92. Dr. Jacob Steinberg, Department of Mathematics, The Technion, Haifa, ISRAEL

93. Mr. C. J. Swet, Route 4, Box 258, Mt. Airy, Maryl and 21771

94. Professor R. Viskanta, School of Mechanical Engineering, Purdue University, Lafayette, Indiana 47907

95. Professor Eitan Wacholder, Department of Nuclear Engineering, The Technion, Israel Institute of Technology, Haifa, ISRAEL

96. Dr. Ray A. Waller, S-1, Statistics, Los Alamos National Laboratory, P.0. Box 1663, Los Alamos, New Mexico 87545

97. Professor Mary Fanet Wheeler, Department of Mathematics, Rice University, Houston, Texas 77001

98. Dr. Stunic Zlasko, Technoloski fakultet, Universitet u Banja Luci, 78000 Banja Luka, YUGOSLAVIA

99. Dr. Gideon Zwas, Department of Mathematics, Tel Aviv University, Tel Aviv, ISRAEL

100. Office of Assistant Manager for Energy Research and Development, Department of Energy, Oak Ridge Operations Office, Oak Ridge, Tennessee 37830

101- Given distribution as shown in TIC-4500 under Mathematics and 406. Computer category. 